Proliferation Resistance Criteria for

Fissile Material Disposition

Donald A. Close

Bryan L. Fearey

Jack T. Markin

Debra A. Rutherford

Ruth A. Duggan*

Calvin D. Jaeger*

Dennis L. Mangan*

Ronald W. Moya*

Lonnie R. Moore*

Robert S. Strait ${ }^{* *}$ 


\section{DISCLAIMER}

This report was prepared as an account of work sponsored by an agency of the United States Government. Neither the United States Government nor any agency thereof, nor any of their employees, make any warranty, express or implied, or assumes any legal liability or responsibility for the accuracy, completeness, or usefulness of any information, apparatus, product, or process disclosed, or represents that its use would not infringe privately owned rights. Reference herein to any specific commercial product, process, or service by trade name, trademark, manufacturer, or otherwise does not necessarily constitute or imply its endorsement, recommendation, or favoring by the United States Government or any agency thereof. The views and opinions of authors expressed herein do not necessarily state or reflect those of the United States Government or any agency thereof. 


\section{DISCLAIMER}

Portions of this document may be illegible in electronic image products. Images are produced from the best available original document. 


\title{
PROLIFERATION RESISTANCE CRITERIA FOR FISSILE MATERIAL DISPOSITION
}

\author{
by \\ Donald A. Close, Bryan L. Fearey, Jack T. Markin, Debra A. Rutherford, \\ Ruth A. Duggan, Calvin D. Jaeger, Dennis L. Mangan, Ronald W. Moya, \\ Lonnie R. Moore, and Robert S. Strait \\ Safeguards and Security Project Team
}

\begin{abstract}
The 1994 National Academy of Sciences study "Management and Disposition of Excess Weapons Plutonium" defined options for reducing the national and international proliferation risks of materials declared excess to the nuclear weapons program. This report proposes criteria for assessing the proliferation resistance of these options. The criteria are general, encompassing all stages of the disposition process from storage through intermediate processing to final disposition including the facilities, processing technologies and materials, the level of safeguards for these materials, and the national/subnational threat to the materials.
\end{abstract}

\section{INTRODUCTION}

This report discusses criteria for assessing the proliferation resistance of the materials, technologies, and facilities composing the options for disposition of fissile materials from surplus weapons. As stated by the 1994 National Academy of Sciences (NAS) study "Management and Disposition of Excess Weapons Plutonium," "the primary goal in choosing options for the management and disposition of excess weapons fissile materials should be to minimize the risks to national and international security." The NAS divides this goal into the following three objectives: reducing the risk of proliferation by unauthorized parties, reducing the risk of reintroduction of the materials into the arsenals from which they came, and strengthening national and international control of fissile materials. The NAS study also recognized the importance of considering the proliferation resistance inherent in all phases of disposition from the current state of the materials through processing to final disposal. In addition, the study considered the implications of the disposition of materials from US excess weapons as a model for the ultimate disposition of fissile materials, both in weapons and in commercial fuel cycles worldwide, recognizing that each country will view disposition options in the context of their specific fuel cycle plans. 
Our report endorses this broad view of proliferation resistance, proposing criteria for evaluating the proliferation resistance of plutonium disposition options that 1) encompass all stages of disposition from storage through intermediate processing to final disposition, 2) consider the varying threat and safeguards environment in each country, and 3) accommodate the varied nuclear fuel cycle plans of each country.

\section{COMPONENTS OF PROLIFERATION RESISTANCE}

The proliferation resistance of a disposition option is determined by the material form; the physical access afforded by the technology or facility, or both, that processes or stores the material; the level of safeguards and security that are applied; and the national/subnational threat to the material. All of these factors affect the resources and technical complexity for acquiring, transporting, and processing the material for use in a nuclear explosive. Because any disposition option is a time-variant path from the current state of the material to the final disposition state, the total proliferation resistance is a function of the proliferation resistance at each stage. The spent fuel standard (see Appendix) suggested by the NAS focuses only on the form of the surplus fissile material and only in its final state. It does not encompass other components of proliferation resistance nor the steps of disposition leading up to the final disposal.

\section{A. Material Form}

The form of the material in terms of its radiological, chemical, and physical characteristics affects the difficulty of acquiring the material and processing it for use in a nuclear explosive. Materials such as spent fuel that are highly radioactive cannot be handled directly, requiring instead shielding and remotely operated equipment to avoid lethal radiation doses. This increases the technical complexity of both acquisition and processing of these materials.

The technical complexity and time required to process the material to a form usable in a nuclear explosive depend on the chemical form. Materials such as plutonium metals, oxides, or carbides require limited or no processing. Low concentrations of plutonium in spent fuel or other waste forms require more complex processing equipment and longer times to separate fission products and other matrix materials to obtain plutonium in sufficient quantity for a nuclear explosive.

Physical form, especially size and weight, affects proliferation resistance in terms of the difficulty of moving the material to a location where it can be processed. For example, plutonium in the form of containers of oxide powder is readily transportable, whereas plutonium in the spent fuel assembly of a light-water reactor requires special equipment for lifting, handling, and transport.

\section{B. Physical Access}

Ease of access to material depends on the number and kinds of barriers surrounding the material locations and the extent to which penetrations in these barriers are sealed or controlled. Clearly, those facilities in which workers have limited or no access to material provide greater barriers to the material. For example, material temporarily stored in a receiving area is more 
accessible than material in long-term storage in a vault or in a geologic repository. In processing facilities, more barriers are provided by modern automated facilities where control is remote and personnel access is not required than by older facilities with hands-on access through glove boxes. Although such barriers increase proliferation resistance for the contained materials, the remoteness of the materials complicates the materials accounting aspects of safeguards.

\section{Safeguards and Security}

The application of domestic and international safeguards will vary from country to country. Domestic safeguards generally consist of materials control and accounting and physical protection measures with the goal of detecting and interrupting unauthorized attempts to access nuclear materials. International safeguards consists of verifying a state's system of accounting using materials accounting methods complemented by containment and surveillance. The international safeguards regime does not have a role of protecting materials; instead, it confirms the correctness of the states' declarations.

The DOE, the Nuclear Regulatory Commission (NRC), and the International Atomic Energy Agency (IAEA) have developed criteria for evaluating the relative attractiveness of nuclear materials for use in weapons. These criteria determine a graded safeguards approach wherein materials that are most readily used for nuclear explosives purposes are assigned increased safeguards. The criteria are generally related to the amount of the material required for a single weapon (significant quantity), the time to process the material to a weapons-usable form, and the technical difficulty of processing to this form.

1. DOE. The DOE assigns attractiveness levels to the various forms of plutonium according to the amount of processing to obtain weapon-usable material. These levels in order of decreasing attractiveness are 1) assembled weapons and test devices; 2) directly convertible materials such as pits, buttons, and ingots; 3 ) high-grade materials such as oxides, carbides, and nitrates; 4) low-grade materials such as process residues; and 5) highly irradiated forms. A graded safeguards approach is applied with the higher attractiveness levels and larger material amounts receiving more stringent materials accounting and physical protection. The highest level of protection is applied to attractiveness level 1 materials in amounts of $2 \mathrm{~kg}$ or more. The lowest level of protection is applied to irradiated forms such as spent fuel.

2. NRC. The NRC also applies a graded approach to materials accounting and physical protection with more stringent measures applied to increasing amounts of plutonium. Amounts of plutonium in excess of $2 \mathrm{~kg}$ receive the strongest protection measures. However, for plutonium in self-protecting material, defined as radioactive material with a total external radiation dose rate in excess of $100 \mathrm{rems} / \mathrm{h}$ at 3 feet, the materials accounting and physical protection requirements are reduced.

3. IAEA. The IAEA defines a significant quantity of plutonium as $8 \mathrm{~kg}$ and prescribes materials accounting and containment/surveillance measures according to the attractiveness of the material for use in a weapon. The attractiveness criteria consider the difficulty of processing 
the material and the time required to process it. The safeguards must meet timeliness and detection probability goals based on the material form. The loss of a significant quantity of plutonium in separated form must be detected with high probability within 1 month. The loss of a significant quantity of plutonium in spent fuel must be detected with high probability within 3 months.

\section{Conflicts Between the Proliferation Resistance Components}

Material form, physical access, and safeguards are interrelated with variations in one component affecting the proliferation resistance of the others. Indeed, these components of proliferation resistance may sometimes be in conflict such that increases in the proliferation resistance of one component decreases the effectiveness or increases the cost of another component. For example, materials in item form are more readily safeguarded than materials in bulk form where measurement uncertainties complicate precise accounting for the material; restrictions on physical access lower the threat of theft while limiting the ability to confirm the continued presence of the material; and material forms that are radioactive improve the selfprotection of the materials while complicating the problem of measuring the material. This suggests that selection of a disposition option should include an examination of the tradeoffs between all of the proliferation-risk components.

\section{PROLIFERATION RESISTANCE OF DISPOSITION PATH}

The level of proliferation resistance will vary as the material moves from its initial state through processing (if needed) to final disposal. In some instances, material might remain in storage for an extended period with no change in proliferation resistance. But in other instances the material could be removed from storage, transported, and processed in a bulk facility, where safeguards are technically more difficult to apply, with a consequent reduction in resistance.

The NAS study identified the need for proliferation resistance at three stages in the disposition process.

Storage. "The security offered by indefinite storage against the risks of breakout and theft is entirely dependent on the durability of the political arrangements."

Handling. "Although options [for final disposition] decrease the long-term accessibility of the material for weapons use, they could increase the short-term risks of theft or diversion because of the required processing and transport steps."

Recovery. (The spent fuel standard) "We believe that the options for long-term disposition of weapons plutonium should ... make this plutonium as inaccessible for weapons use as the much larger and growing quantity of plutonium that exists in commercial reactors." 


\section{PROLIFERATION RESISTANCE AND THREAT}

The level of the proliferation threat depends on the country and can include 1) insiders working in a facility and employing either violence or stealth, 2) outsiders such as criminals or terrorists, and 3) a national threat posed by a nation's decision to employ plutonium in a weapons program. The technical strength of the criminal or terrorist threat in terms of ability to access and process these materials or the political decision of a nation to initiate a weapons program strongly affects the proliferation resistance of the disposition options.

The following summary of threats and safeguards in selected states indicates the diversity of proliferation environments to be addressed by any program for global disposition of fissile materials.

\section{A. Nonproliferation Treaty (NPT) Countries with Full-Scope Safeguards Agreements(INFCIRC 153)}

These non-nuclear weapons states, including Canada, Germany, Belgium, Italy, Sweden, and Japan, have all signed the NPT and maintain States Systems of Accounting and Control (SSAC) that are consistent with IAEA standards (INFCIRC 153) and are verified by the IAEA. In countries that are members of the Commission of European Communities, the SSAC is maintained by the EURATOM safeguards agency, which conducts independent inspections as well as joint inspections with the IAEA. In addition, all of these NPT countries apply physical protection measures consistent with the IAEA guidance (INFCIRC 225) that sets international standards for such measures. Countries in this category could be considered to have an environment with a low proliferation threat and a high level of safeguards.

\section{B . France, UK, and US}

These nuclear weapons states have signed the NPT and have submitted a list of commercial nuclear facilities that the IAEA can select for full or limited inspections under Voluntary Agreements with these states. These states maintain an SSAC and their physical protection conforms to INFCIRC 225 standards. In addition, their weapon materials are also under as strong safeguards and security measures as are the materials in their commercial fuel cycles. These countries have environments with a low proliferation threat and a high level of safeguards.

\section{States of the Former Soviet Union}

Russia has signed the NPT and, as a nuclear weapons state, accepts limited inspections of some nonweapons facilities under a Voluntary Agreement with the IAEA. Although Russian accounting for nuclear materials has traditionally been limited, physical protection measures were strong. However, there are recent signs that the physical protection system may be eroding. Kazakhstan and Ukraine have similar weaknesses in materials accounting. However, Kazakhstan has signed an agreement with the IAEA to apply full-scope safeguards to all nuclear facilities, and Ukraine is negotiating inspections by the IAEA. Acceptance of IAEA safeguards will require both countries to establish an improved SSAC. The criminal and terrorist threats in these countries have been much higher than in the full-scope NPT countries. 


\section{States with Limited Inspections by the IAEA (INFCIRC 66)}

India, Pakistan, and Israel have not signed the NPT but have limited agreements with the Agency for safeguards on selected materials in their fuel cycles. Thus, all nuclear materials in these countries are not under international safeguards, and the level of safeguards in these countries is significantly less than in the full-scope countries. Argentina and Brazil have formed a regional safeguards system (ABACC) for mutual inspections and are negotiating NPT agreements with the IAEA. The threat of continued proliferation is, of course, high in India, Pakistan, and Israel where all three are suspected to have nuclear weapons production capability with a limited stockpile, whereas in Argentina and Brazil the proliferation trend is reversed.

\section{E. Threshold Nuclear States}

Iraq and North Korea, although signatories of the NPT, are clearly states that have had proliferant nuclear activities. Iran is an NPT signatory but is suspected of having a clandestine nuclear weapons program.

\section{THE "SPENT FUEL STANDARD"}

The spent fuel standard defines proliferation resistance in terms of just the self-protecting attributes of the material ( radioactivity, size, and weight) and its need for chemical processing to obtain plutonium (see Appendix). However, this emphasis on material form ignores other aspects of proliferation resistance including 1) the proliferation resistance factors: physical access and safeguards; 2 ) the indigenous threat of unauthorized use of the material for weapons purposes within a State; 3 ) the threat of reintroduction of the materials into a State's nuclear arsenal and 4) the need to address the proliferation resistance of the complete disposition path.

The focus of the spent fuel standard on material attributes neglects the two important factors, physical access and safeguards, that affect proliferation resistance by limiting unauthorized access to the material. Physical access to material is affected by facility or natural barriers such as storage vault walls or burial in a geologic repository. Although the radiation field of a spent fuel assembly contributes to the difficulty of accessing it, the radioactivity declines with time. Access is further restricted by domestic safeguards and security measures that detect and interdict unauthorized attempts to access material.

As discussed in Section IV, the proliferation resistance of material to unauthorized use is strongly affected by the threat environment in the country where the materials reside. Thus, the value of the material form, physical access barriers, and safeguards in improving proliferation resistance cannot be known until these factors are measured against the threat (criminal, terrorist, or national). Clearly, the proliferation resistance of spent fuel in Iraq, Russia, and the US would vary with each country even though the material attributes are similar in each case. 
In addition to proliferation resistance of materials to unauthorized use, the reintroduction of fissile materials into the arsenals of the nuclear weapons States is also a major concern. Declared nuclear weapons States all have operational reprocessing capabilities for extracting plutonium from spent fuel and have performed this process for years. Therefore a spent fuel standard does not prevent these States from reintroducing the materials into their weapon stockpiles. At most it may delay such a move. The benefits of such a delay can only be realized if international safeguards are in place to provide detection. Nuclear weapons States could of course simply reprocess spent fuel from civilian reactors, which the Russians have traditionally done for weapons materials and which other nations are doing for plutonium for civilian reactor fuel.

The spent fuel standard focuses only on the final disposition state of the material, ignoring the proliferation resistance of the prior storage and processing stages necessary to reach the spent fuel end-state. For example, in some countries plutonium could be considered more secure in a storage vault than in an alternative that lowers proliferation resistance by removing plutonium from storage, processing it in a bulk facility where safeguards are technically more difficult, and transporting it to a reactor. The net decrease in proliferation resistance during this process may exceed any added resistance value of the spent fuel form.

Finally, adoption of a spent fuel standard neglects the implication that the proliferation resistance criteria adopted for the US plutonium disposition process could serve as a model for global fissile material disposition. Thus, it may not be beneficial for the US to adopt a standard for judging plutonium disposition that cannot encompass the policies of other important holders of plutonium such as France, Japan, Russia, and the UK. Indeed, without the reciprocal cooperation of Russia we have not appreciably reduced the nuclear danger. A more broadly based set of criteria are needed, flexible enough to accommodate a diversity of disposition options, while assuring a global increase in proliferation resistance for plutonium.

\section{PROPOSED CRITERIA FOR MEASURING PROLIFERATION RESIS. TANCE OF PLUTONIUM DISPOSITION OPTIONS}

The following criteria are proposed as comprehensive measures of the proliferation resistance of the fissile materials disposition process in an arbitrary threat/safeguards context.

\section{A. Factors Affecting the Technical Difficulty of Acquiring Material}

1. Physical Access. The physical location of the material can affect its accessibility to a proliferator. Natural, facility, or process equipment barriers are all factors in determining ease of access. For example, spent fuel in a geologic repository is clearly less accessible than spent fuel in a pond.

(Measures: number and types of barriers between threat and material) 
2. Safeguards/Physical Protection. The detection and prevention of an access attempt depends on the levels of safeguards and physical protection at the facility. In general, safeguards are more easily applied and more readily verified when materials are in the form of discrete, uniquely identifiable items (such $\mathrm{PuO}_{2}$ in sealed containers) as opposed to materials in bulk form in a chemical processing facility.

(Measure: quality of safeguards, e.g., physical protection consistent with INFCIRC 225, safeguards consistent with DOE Order 5633.3B, verification consistent with IAEA INFCIRC 66 or 153)

3. Self-Protection Aspects of the Material. Characteristics of the material that can complicate gaining physical control of a significant quantity of the material. For example, radioactivity of spent fuel increases the technical complexity of acquiring the material.

(Measures: rads $/ \mathrm{h}$ at $1 \mathrm{~m}$, number of items for 1 significant quantity)

4. Physical Form. Characteristics of the material that increase the technical complexity of its transport to a location where it can be processed are the size, weight, and radioactivity of the materials required for a significant quantity. Clearly, a spent fuel assembly is more difficult to transport than a container of separated plutonium.

(Measures: size, weight, and radioactivity)

\section{B . Factors Affecting the Difficulty of Processing the Material}

1. Technical Difficulty of Processing. The technical complexity of recovering a significant quantity of the material through, for example, chemical reprocessing and isotopic enrichment is a measure of the difficulty of processing the material. (Measures: concentration of plutonium and chemical form)

2. Time of Processing. The time to recover a significant quantity will depend on the available technology, the initial form of the material, chemical processes, and the amount of material that must be processed to achieve a significant quantity. Clearly, materials having a low concentration of plutonium will require longer processing times.

(Measure: time to process $1 \mathrm{SQ}$ )

3. Financial and Technical Infrastructure. This is the infrastructure required to support the scientific and engineering knowledge needed to design and construct the processing facilities.

(Measure: cost of processing facility)

The relative importance of these criteria varies with the threat and the proliferation environment. For example, financial and technical infrastructure and physical form are not particularly important if the threat is the reintroduction to a weapons state's stockpile; instead, international safeguards, time of processing, and physical access may be the key criteria. On the other hand, financial and technical infrastructure and physical form may be the key criteria for a threshold nuclear state. 


\section{SUMMARY}

Criteria for evaluating the proliferation resistance of proposed disposition processes for plutonium should be sufficiently comprehensive to include resistance at all stages of the disposition process as well as resistance factors that depend on the threat and safeguards environment in each country. In this report we propose general proliferation resistance measures that encompass these factors. We have specifically avoided the concept of a single criterion such as the "spent fuel standard" that addresses only the end stage of the disposition process and does not address sensitivity to the threat or safeguards environment in a country. 


\title{
APPENDIX
}

\author{
Definition for the "Spent Fuel Standard"
}

\section{INTRODUCTION}

The purpose of this appendix is to propose an interpretation and description of the Spent Fuel Standard as identified in the National Academy of Sciences (NAS) study entitled "Management and Disposition of Excess Weapons Plutonium." In discussing long-term disposition, the NAS stated, "We believe that options for the long-term disposition of weapons plutonium should seek to meet a 'spent fuel standard'-that is, to make this plutonium roughly as inaccessible for weapons use as the much larger and growing quantity of plutonium that exists in spent fuel from commercial reactors."

To some who equate a standard to an acknowledged measure of comparison for quantitative or qualitative values, the use of the word Standard by the NAS was perhaps a misnomer because no such acknowledged measures of comparison exist that either define spent fuel or the methods and specifics for the storage of spent fuel. To others who use the more loose definition of a standard as being of average but acceptable quality, the use of the word is appropriate.

Key in the NAS description of the Spent Fuel Standard is the word inaccessible. In this context of proliferation resistance, inaccessibility of spent fuel from commercial reactors results in the material being in a large, radioactive, and chemically unattractive form as well as in difficult-to-access locations and under certain domestic and international institutional regulations and requirements. An alternative way to define this inaccessibility or proliferation resistance is with the form of the material, the difficult-to-access locations, and the level of safeguards and security (both for domestic and international purposes) applied to the material. The form of the material reflects the intrinsic properties of the material; the storage location and safeguards and security applied define the extrinsic environment of the material.

An essential element in assuring the proliferation resistance of spent fuel is the safeguards and security applied to the material. The form of the material alone does not provide proliferation resistance. Proper domestic safeguards and security will address the threat of theft or diversion by subnational groups, terrorists, or disgruntled employees. Proper international safeguards, as practiced by the International Atomic Energy Agency (IAEA), will address the threat of diversion of the material by the host state where the material is stored.

For the Fissile Materials Disposition Program, it seems prudent to equate the Spent Fuel Standard with the intrinsic properties or form of the material only. Doing this will allow facility and process designers to judge the various options to determine whether the processed material has an equivalent nature as spent fuel. Because the extrinsic environment of the storage location and safeguards and security are interrelated and site dependent, appropriate institutional means can be achieved. 
With this interpretation of the NAS report, the definition and discussion presented here focus on the form of the material to be disposed and do not directly address the level of safeguards and security to be applied. The definition does, however, assume that the level of safeguards and security (both domestic and international) currently applied to commercial spent fuel will likewise be applied to the processed excess weapons material. This report recognizes that the form of the material is just one component of the overall proliferation resistance, and that the total proliferation resistance includes a comprehensive and systematic program of security and safeguards appropriate for the form of the material being stored, transported, or disposed.

This discussion should not be interpreted as a definition of "spent fuel," inferring that all material must meet the characteristics identified below to be classified as spent fuel because some irradiated fuel, classified as spent fuel, exists within the DOE complex. Rather, the sole intent of this document is to provide guidance as to the properties that surplus processed plutonium should have to allow it to be placed under those safeguards and security practices normally applied to spent fuel as appropriate for both domestic and international purposes.

The proposed spent fuel standard described here consists of four parts. These include the radiological, physical, chemical, and nuclear properties of a disposal option that make processed excess weapons plutonium inaccessible for recovery as commercial spent fuel. Three of the characteristics, namely radiological, physical, and chemical, directly influence the particular requirements, regulations, and practices for the application of safeguards and security for both domestic and international purposes; therefore, the material needs to meet all three characteristics to fall under the Spent Fuel Standard. The nuclear properties of the plutonium (isotopic composition) have only a secondary effect. In the discussion that follows, it is noted that domestic safeguards and security-the purpose of which is to detect, delay, and respond to the threats of a terrorist, subnational group, or disgruntled insiders-is under the control of the facility operator, the application of international safeguards - the purpose of which is to provide assurance of the timely detection of diversion of the material by the state itself-is under the responsibility of the IAEA. Domestic safeguards and security vary from state to state and are driven to a certain extent by the cultural and economic environment of the state; IAEA safeguards generally are consistent among states. The discussion below focuses on practices of the US.

Radiological Properties: Both the DOE and NRC regulations allow reduced safeguards and security practices if the radiation level of the material exceeds a certain high-level dose rate. When the dose rate falls below the allowed limit, then more stringent safeguards and security measures have to be implemented. This is important for long-term storage activities. For the application of the IAEA safeguards, essentially no credit is given for high levels of radiation except indirectly as associated with the timeliness associated with the reprocessing or chemical separation of the material, as noted below. IAEA safeguards will be implemented indefinitely on spent fuel, even after disposal in a geological repository, for example, unless international agreements are modified. (It should be noted that, due to the lack of operating geological repositories, IAEA safeguards have not yet been applied to such facilities. Studies are underway to assess technologies appropriate for IAEA safeguards at such facilities.) 
Physical Properties: Large, bulky, and heavy items facilitate the implementation of safeguards and security measures, both from domestic and international standpoints. Domestically, theft-detection capabilities are significantly enhanced by large physical properties (size and weight) because movement of the material is detected readily and the need to use heavy equipment to remove such items allows for a reduction in response force timeliness to prevent the theft of the material. Internationally, large items facilitate the item accountancy measures as well as significantly facilitating the identification of item movement using containment and surveillance measures. However, it should be noted that the requirements and regulations that need to be followed for large and bulky items are no different than for small and light-weight items; it is just easier to implement the measures needed to meet the requirements.

Chemical Properties: The chemical properties of the nuclear material impact the domestic safeguards and security requirements because the extent of the processing required to convert nuclear materials to a nuclear explosive device determines the attractiveness rating of the material (Levels A-E) that subsequently is used to determine the level of safeguards and security that must be provided (Categories I-IV). Although the timely detection of diversion through the application of international safeguards is still required, international safeguards inspections are reduced in effect by the time needed to perform the chemical separation of plutonium. Thus, IAEA safeguards are less intense and less intrusive. It should be noted that IAEA safeguards are still required.

\section{RADIOlOGICAL, PHYSICAL, AND CHEMICAL PROPERTIES}

The following paragraphs provide a more detailed description or definition of the "spent fuel standard" for the three properties just mentioned, including discussions on the nuclear properties or isotopic content of the material. The property is defined in a qualitative manner followed by a discussion of quantitative attributes illustrating how spent fuel from commercial light-water reactors (LWR) (both pressurized water and boiling water) and Canadian deuterium uranium (CANDU) reactors satisfies the basic precepts of the proposed standard.

\section{A. Radiological Properties}

The proliferation resistance of the "proposed spent fuel standard" is engendered in the extremely high radiological dose rate at a distance from the spent fuel assembly. This dose rate is sufficiently high to disable or kill unprotected humans who may approach the material and remain in its vicinity long enough to effectively divert or recover the plutonium from the material without specialized shielding equipment. Furthermore, this level of radioactivity is persistent and remains effective for several human generations in the case of commercial spent fuel from LWRs. Because specialized equipment is needed for diversion and recovery operations, the level of effort and the quantity of resources are greatly increased during all phases of recovery operations until the residual radioactivity is isolated from the excess plutonium.

The high level of radioactivity of spent fuel includes an additional proliferation-resistant feature, which is visibility. Typical levels of spent fuel radioactivity are sufficiently high to 
make it far easier to monitor and detect this material than non-irradiated nuclear material such as unprocessed weapons-grade plutonium. Easier detection therefore facilitates safeguarding efforts and accountability.

The key radiological properties for the spent fuel standard are the following:

a) the radiological dose rate from the plutonium processed from excess weapons is sufficiently high to be disabling or lethal to unprotected humans who approach the processed plutonium and remain in its vicinity long enough to effectively divert or recover the plutonium, and

b) this level of radioactivity is persistent and remains effective for several human generations.

\section{B . Examples of Commercial Fuel Radiological Properties}

The US Nuclear Regulatory Commission and the DOE consider special nuclear materials emitting more than $100 \mathrm{rad} / \mathrm{h}$ at $1 \mathrm{~m}$ to be sufficiently self-protecting to require a lower level of safeguards. The justification for this is that levels of radiation of this magnitude are large enough to cause severe illness to an individual after only a few hours of exposure and a high probability of death within 2-6 h of exposure. Typical biological effects of whole body doses are listed below in Table 1.

TABLE 1. Expected Biological Effect Due to a Whole Body Exposure

\begin{tabular}{|c|c|}
\hline Acute Dose & Expected Biological Effect \\
\hline $25-50 \mathrm{rem}$ & First signs of changes in blood lymphocytes \\
\hline $100-200 \mathrm{rem}$ & $\begin{array}{l}5-50 \% \text { of exposed population exhibit vomiting } \\
<10 \% \text { hospitalized for } 60-90 \text { days } \\
\text { Expected } 80 \% \text { recovery }\end{array}$ \\
\hline $400 \mathrm{rem}$ & $\begin{array}{l}50-100 \% \text { of exposed population exhibits vomiting } \\
\text { Up to } 90 \% \text { hospitalized for } 60-90 \text { days } \\
\text { Up to } 80 \% \text { death in } 3 \text { weeks to } 2 \text { months }\end{array}$ \\
\hline $800-3000 \mathrm{rem}$ & $100 \%$ death expected within 3 months \\
\hline $2000-3000$ rem & $\begin{array}{l}\text { Fatal within } 3 \text { to } 10 \text { days for } 100 \% \text { of the exposed } \\
\text { population }\end{array}$ \\
\hline$>10,000 \mathrm{rem}$ & Fatal within 48 hours for $100 \%$ of the exposed population \\
\hline
\end{tabular}

1. LWR Spent Fuel Radiological Characteristics. The radiological characteristics of spent fuel are controlled primarily by the amount of burnup and the quantity of fuel. Typical LWR burnups are 30,000 MWd/MTHM (megawatt-days per tonne of heavy metal), with the trend in modern designs to increase burnups to 50,000-60,000 MWd/MTHM. Each fuel assembly contains approximately $400 \mathrm{~kg}$ of heavy metal. Figure 1 shows a plot of the radioactivity emitted from a commercial spent fuel assembly irradiated to $33,000 \mathrm{MWd} / \mathrm{MTHM}$ and containing $412 \mathrm{~kg}$ of heavy metal. As seen from this figure, the dose rate at $1 \mathrm{~m}$, ten years after removal from the reactor, is on the order of $1000 \mathrm{rem} / \mathrm{h}$. Exposure to this amount of irradiation for $1 \mathrm{~h}$ will cause death. 


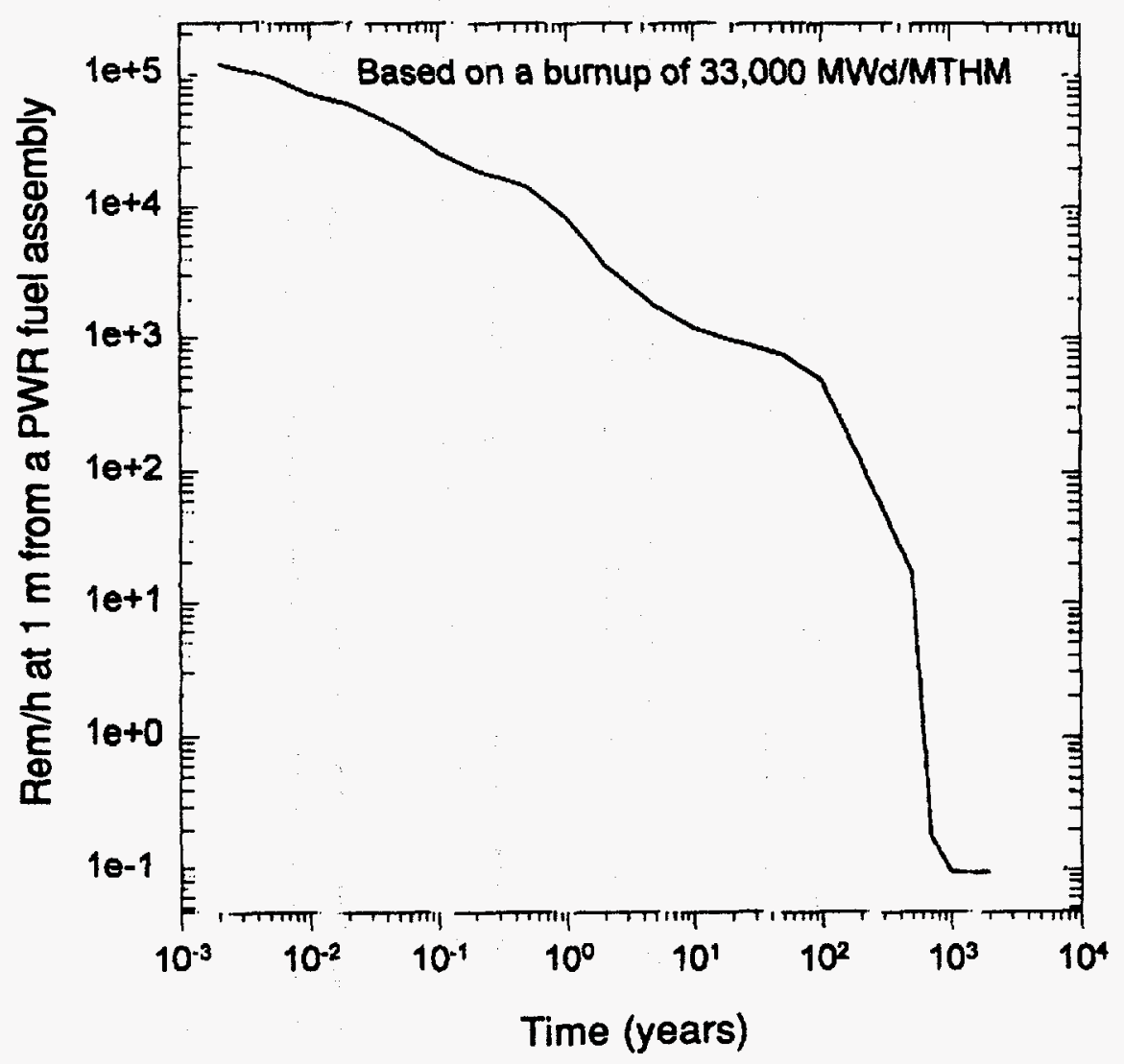

Fig. 1. Dose rate at $1 \mathrm{~m}$ from an LWR fuel assembly irradiated to $33,000 \mathrm{MWd} / \mathrm{MTHM}$ containing $412 \mathrm{~kg}$ of heavy metal (HM).

An interesting feature of Fig. 1 is that after about 100 years, the radioactivity of the fuel tends to decay with an approximate 30-yr half life, mirroring the half-lives of cesium-137 and strontium-90. Thus, the "self protecting" nature of the spent fuel is effectively lost after 200 to 300 years. The decay of the radiation field, therefore, requires a disposal or disposition strategy that effectively prevents human access to the material once the self-protecting nature is lost.

2. CANDU Spent Fuel Properties. The dose rate from spent fuel trays from CANDU reactors (which contain 24 fuel assemblies) are substantially lower than those from commercial LWRs due to the use of natural uranium and the much lower burnup $(7300$ MWD/MTHM). Typically, a single spent fuel assembly will exceed the $100 \mathrm{rem} / \mathrm{h}$ limit for only about 3 years under these typical irradiation conditions. (Encapsulating the assemblies in integral assemblies into spent fuel trays increases the dose rate substantially.) Even though the quantity and persistence of the radiation levels are substantially below those of LWRs, this material can be made adequately proliferation resistant by providing enhanced safeguards. Similarly, the availability of the selected disposition option must coincide with the total proliferation resistance provided by the radiation level and the applied security level. 


\section{Physical Properties of the Spent Fuel Standard}

The physical properties of plutonium processed from excess weapons must provide both inherent proliferation resistance and facilitate future safeguarding efforts. Furthermore, the physical nature of the material alone is not sufficient to make the material proliferation resistant. The proliferation resistance occurs because of the extremely high levels of radioactivity (as described above) existing simultaneously with physical characteristics that make the material difficult to handle and easily accountable.

Thus, excess weapons plutonium must be processed and placed in a physical form assuring that the material

a) consists of an intact integral assembly of components that is individually identifiable and accountable by item accounting methods and

b) is sufficiently large and heavy to be impossible for an individual to carry or move the intact assembly without the aid of machinery.

\section{Examples of Physical Properties of Spent Fuel Standards}

1. Physical Characteristics of LWR Spent Fuel. LWR fuel assemblies consist of large heavy structures that require special cranes and lifting devices to move. Typically, a fuel assembly consists of an intact collection of 126-331 fuel pins or rods, held together by grids, grid spacers, and special locking devices. Each assembly weighs from $250-840 \mathrm{~kg}$ and has lengths varying from 3.2-4.8 m depending on the reactor design. Again the current trend for the design of new, modern power reactors is to increase the size and weight of the fuel assemblies. These assemblies are sufficiently large to provide proliferation resistance by facilitating item accounting and heavy enough to require mechanical assistance to move. This translates directly into the frequency of IAEA monitoring of spent fuel cooling ponds because special equipment is needed to remove the material and because it is large enough to be difficult to conceal its removal.

2. Physical Characteristics of CANDU Spent Fuel. CANDU fuel assemblies are much smaller than those used in pressurized water reactors and boiling water reactors. A typical CANDU fuel assembly consists of 37 fuel pins having an overall length of 19.5 in., is $4 \mathrm{in}$. in diameter, and weighs $19.5 \mathrm{~kg}$. Nevertheless, upon removal from the reactor, the fuel assemblies are stored in trays containing 24 assemblies, resulting in a total weight of $468 \mathrm{~kg}$. Each tray has dimensions of approximately $1.4 \times 1.2 \times 0.1 \mathrm{~m}$ and weighs about $500 \mathrm{~kg}$. Typically, two of these trays are sealed together using random coil seals. Thus, by this method of collecting individual assemblies into larger tray configurations, the conditions for the spent fuel standard are met because each tray/trays consists of an intact collection of fuel assemblies, and they are large enough and heavy enough to facilitate item accounting and require special equipment to move. 


\section{E. Chemical Properties/Dilution of the Spent Fuel Standard}

The chemical properties of the spent fuel standard that make excess weapons plutonium proliferation resistant are associated with the difficulty of recovering plutonium from the processed fuel. In addition, the proliferation-resistance property is greatly enhanced due to the presence of extremely high radiological levels existing simultaneously with special and sophisticated technology required to efficiently recover the plutonium with adequate quality. The essential chemical properties for the spent fuel standard are the following:

a) the plutonium content in material processed from excess weapons shall be diluted and homogeneously dispersed in a solid matrix that is enclosed in a sealed package. [It is suggested that the weight percent of plutonium in the spent fuel standard be less than several to many weight percent, (i.e., the plutonium weight percent of the processed material should be less than 48 wt\% of the heavy metal content)] and

b) the sealed package is made of a metal or other chemical form that is substantially different from the plutonium chemical form.

\section{F. Examples of Chemical Properties of the Spent Fuel Standard}

1. LWR Spent Fuel Chemical Characteristics. LWR reactors use fuel-formbased uranium dioxide fuel pellets enclosed in zircaloy cladding. Initially the uranium is enriched to 2.5-3.5 wt\% U-235, and it is homogeneously distributed (on an atomistic scale) within the remaining U-238 oxide fuel matrix. After irradiation, the fissile (plutonium plus $\mathrm{U}-235$ ) content is about $1.6 \mathrm{wt} \%$. In a plutonium burner concept using mixed oxide fuel, the concentration of the remaining fissile material will be larger by about a factor of two than the concentration in currently existing commercial reactors due to the initial higher concentrations of plutonium in the mixed oxide fuel. Thus, the fissile content after irradiation will be about 3.2-4.0 wt\% after irradiation. In summary, commercial spent fuel from an LWR meets the spent fuel standard by resulting in a solid plutonium oxide fuel homogeneously distributed throughout the fuel pellets that are enclosed in a metal cladding. Because the plutonium/fissile concentration is so small (a few percent), highly efficient recovery methods and sophisticated equipment are required to obtain usable quantities of plutonium.

2. CANDU Spent Fuel Chemical Characteristics. The CANDU fuel form is very similar to $L W R$ fuel except that the fissile concentrations are substantially lower, $0.6 \mathrm{wt} \%$ plutonium of the total heavy metal mass after irradiation. Thus, this fuel is also sufficiently dilute and chemically difficult to recover to provide the same level of proliferation resistance, with respect to chemical characteristics, as commercial spent fuel.

\section{NUCLEAR PROPERTIES OF THE "SPENT FUEL STANDARD”}

The key nuclear properties of plutonium that address the proliferation-resistant features are the isotopic content of plutonium. The isotopic mix of typical LWR spent fuel is generally considered to be proliferation resistant due to its low concentration of Pu-239 $(\sim 56 \mathrm{wt} \%)$ and higher concentration of Pu-240 ( 23 wt\%), Pu-241 ( 14 wt\%), and Pu-238 ( 1 wt\%)-all of 
which increase the level of difficulty required to design and fabricate an effective weapon. The level of difficulty increases due to the internal heating caused by alpha decay from $\mathrm{Pu}-238$; the additional neutron source rate due to spontaneous fissions from $\mathrm{Pu}-240$, which increases the likelihood for a weapon to pre-initiate; and the highly penetrating gamma rays from Am-241, which arise from the decay of $\mathrm{Pu}-241$ increasing the handling and fabrication difficulties of LWR plutonium. Weapons grade plutonium is, on the other hand, traditionally $94 \mathrm{wt} \%$ $\mathrm{Pu}-239$. Thus, for these reasons, LWR-like isotopic mixes of plutonium do incrementally increase the proliferation resistance of the material by increasing the level of difficulty in designing and fabricating a weapon.

However, the above difficulty features address incremental characteristics or levels of inconvenience associated with designing an effective nuclear weapon having efficient yields. This is evidenced by the likely fizzile yield (several kilo-tonnes) available from a simple nuclear device (even with pre-initiation caused by high $\mathrm{Pu}-240$ isotopes) resulting in a very large explosion. Thus, in the interest of defining a conservative weapons-proliferation-resistance policy, one should treat virtually any plutonium isotopic mix as capable of being made into a nuclear weapon.

Thus, the spent fuel standard should not treat the isotopic mix of plutonium from disposed excess weapons as a discriminating factor for proliferation resistance. There are, however, incremental levels of inconvenience associated with recovering, designing, and fabricating weapons with LWR-like isotopic mixes.

The isotopic mix of plutonium from disposed excess weapons is not a discriminating factor for prioritizing disposal options.

\section{Example of Nuclear Properties of Commercial Fuel}

LWR Isotopic Nuclear Properties. Table 2 lists typical isotopic concentrations of excess weapons plutonium, LWR spent fuel having a burnup of 33,000 MWd/MTHM, and a CANDU reactor with a burnup of $7300 \mathrm{MWd} / \mathrm{MTHM}$. As described, even though there are differences between excess weapons plutonium and the isotopic mix from spent fuel, none of these isotopic distributions should be considered a discriminating factor.

TABLE 2. Isotopic Content of Plutonium from Spent Fuel from LWRs (Burnup = 33,000 MWd/MTHM), CANDU Reactors (Burnup $=7300 \mathrm{MWd} / \mathrm{MTHM}$ ), and Excess Weapons Plutonium

\begin{tabular}{|l||c|c|c|}
\hline Isotope & $\begin{array}{c}\text { Excess Plutonium } \\
(\%)\end{array}$ & $\begin{array}{c}\text { LWR Spent Fuel } \\
(\%)\end{array}$ & $\begin{array}{c}\text { CANDU Spent Fuel } \\
(\%)\end{array}$ \\
\hline $\mathrm{Pu}-238$ & 0.05 & 1 & 0.08 \\
\hline $\mathrm{Pu}-239$ & 94 & 56 & 66.2 \\
\hline $\mathrm{Pu}-240$ & 6.0 & 23 & 27.1 \\
\hline $\mathrm{Pu}-241$ & 0.4 & 14 & 5.1 \\
\hline $\mathrm{Pu}-242$ & 0.05 & 5 & 1.6 \\
\hline
\end{tabular}

